\title{
Docetaxel with or without estramustine for estramustine refractory castration-resistant prostate cancer: a single institution experience
}

Kazuhiko Nakano*, Shigeyuki Ohta, Kenji Komatsu, Taro Kubo, Akinori Nukui, Kazumi Suzuki, Shinsuke Kurokawa, Minoru Kobayashi and Tatsuo Morita

\begin{abstract}
Background: The significance of combination of docetaxel (DTX) with estramustine phosphate (EMP) in castrationresistant prostate cancer (CRPC) patients remains unclear. In this study, we aimed to retrospectively evaluate the efficacy and toxicity of DTX with or without EMP and to elucidate the significance of DTX and EMP combination therapy in Japanese EMP-refractory CRPC patients.

Methods: To compare the efficacy and toxicity of DTX and EMP, we divided CRPC patients, who were confirmed to be resistant to EMP, into the following two groups: group $D(n=28)$, which included patients treated with DTX (60 $\mathrm{mg} / \mathrm{m}^{2}$, once in every four weeks) alone, and group DE $(n=33)$, which included patients treated with a combination of DTX (60 mg/m², once in every four weeks) and EMP (twice daily oral administration at $280 \mathrm{mg}$ ).

Results: Prostate specific antigen (PSA) response (> 50\% decline in PSA) was observed in six patients (21\%) in group D and eight patients (24\%) in group DE. The median time to progression (TTP) was 12.0 months and 6.2 months and the median overall survival (OS) was 26.4 months and 24.3 months in group D and DE, respectively. There was no statistical difference between the two groups in terms of PSA response, TTP, and OS. The incidence of adverse events of grade 3/4 was low in both the groups, and there was no statistical difference between the two groups.

Conclusions: Although treatment with DTX at $60 \mathrm{mg} / \mathrm{m}^{2}$ was effective and highly tolerated in EMP-refractory Japanese CRPC patients, the DTX and EMP combination therapy might not exhibit any survival benefit for CRPC patients.
\end{abstract}

\section{Background}

The efficacy of docetaxel (DTX) in castration-resistant prostate cancer (CRPC) patients was shown in two clinical trials of TAX 327 [1] and SWOG 9916 [2] in 2004. Thereafter, DTX-based therapies have been used worldwide for treating CRPC patients. TAX 327 reported a median overall survival (OS) of 18.9 months with administration of DTX every three weeks, and SWOG 9916 reported a median OS of 17.5 months with DTX and estramustine phosphate (EMP) combination therapy every three weeks. While these results showed that DTX was more effective than mitoxantrone, they also raised

\footnotetext{
* Correspondence: nknkzhk@jichi.ac.jp

Department of Urology, Jichi Medical University, Yakushiji 3311-1, Shimotsuke-city, Tochigi 3290498, Japan
}

other questions about whether addition of EMP to DTX was effective for CRPC patients. To clarify this point, several clinical trials and one meta-analysis have been performed thus far. While there have been some reports describing the usefulness of DTX and EMP combination therapy [3-5], other reports suggest that the combination treatment is not useful [6]. A preclinical report showed that addition of EMP did not enhance the efficacy of DTX [7], while other preclinical studies confirmed that EMP in combination with DTX exerted beneficial effects in prostate cancer $[8,9]$. Since the views on the efficacy of DTX and EMP combination therapy are controversial, it is important to determine clinically whether or not EMP enhances the efficacy of DTX. 
In considering the patient backgrounds in the clinical trials described above, however, CRPC patients pretreated with EMP were excluded in SWOG 9916, while both patients treated with and without EMP were enrolled in the clinical trials described above ${ }^{4-6}$. Since patients entered in these previous clinical trials were EMP-naive patients or the mixture of EMP-naive and refractory patients, we focused on the efficacy of DTX by the addition of EMP in EMP-refractory CRPC patients in order to examine the modulatory effect of EMP on DTX in clinical setting.

In the present study, we retrospectively compared the efficacy and toxicity of DTX treatment with and without EMP in Japanese EMP-refractory CRPC patients in order to elucidate the significance of the addition of EMP to DTX therapy.

\section{Methods \\ Subjects}

Between July 2003 and October 2010, 90 CRPC patients were pathologically diagnosed with adenocarcinoma of the prostate and treated with DTX at our institution. From this group, $61 \mathrm{CRPC}$ patients who were treated with EMP monotherapy, then confirmed to be resistant to EMP, and received two or more courses of DTX therapy were included in the present analysis. These EMP-refractory CRPC patients were divided into two groups as follows: group D consisting of 28 patients who were treated with DTX without EMP and group DE consisting of 33 patients treated with DTX and EMP combination. The reasons why EMP was not concomitantly administered in group D included adverse events in 16 patients (57\%) and the patient request in 12 patients (43\%). DTX therapy was initiated in patients resistant to androgen deprivation therapy, which uses luteinizing hormone-releasing hormone (LHRH) analogue and antiandrogen. Patients with antiandrogen withdrawal syndrome were excluded from the study. The inclusion criteria were Eastern Cooperative Oncology Group (ECOG) performance status (PS) of two or lower, white blood cell (WBC) count $\geq 1500 / \mathrm{mm}^{3}$, hemoglobin (Hb) $\geq 8 \mathrm{~g} / \mathrm{dL}$, platelet count $\geq 100000 / \mathrm{mm}^{3}$, total bilirubin $\leq$ upper limit of normal (ULN), and aspartate aminotransferase (AST) and alanine aminotransferase (ALT) $\leq 2.5 \times$ ULN.

The patient characteristics by group are shown in Table 1. There was no statistical difference in all parameters between both the groups. The median observation period was 19.5 months (range; 3.0-60.9 months). The median number of DTX treatment course was four in group $\mathrm{D}$ and five in group DE. This study was approved by the institutional review board of Jichi Medical University and written informed consent was obtained from all patients.

\section{Treatment}

We used a modified version of the regimen used in SWOG 9916 [2] as the treatment protocol. Briefly, DTX $60 \mathrm{mg} / \mathrm{m}^{2}$ was administered by intravenous drip infusion for one hour on day one once every four weeks. Further, eight mg of dexamethasone was administered by intravenous drip infusion as premedication before and after treatment with DTX. The treatment course was repeated every four weeks. In group D, DTX alone was administered after confirming the resistance to EMP. Meanwhile, in group DE, DTX and EMP equivalent to the amount administered before DTX therapy was administered after confirming the resistance to EMP. Although $280 \mathrm{mg}$ EMP twice daily was orally administered every day, dose reduction up to $280 \mathrm{mg} /$ day was allowed according to the degree of adverse events. The treatment was continued until progression of disease was observed, and it was stopped after the occurrence of adverse events which made it impossible to continue the treatment or on patient request. Progression of disease was defined as biological progression characterized by the increase in evaluable lesions observed on imaging test or continuous elevation of serum PSA on at least three consecutive measurements.

At the initiation of treatment and before each cycle, medical history of the patient was taken and physical examination, PS evaluation, and hematological examination (blood count, biochemistry, and PSA) were performed at least once every four weeks. Computed tomography (CT) and bone scintigraphy were performed at least once every 16 weeks.

\section{Outcomes}

Primary endpoint was PSA response. According to the recommendations of Prostate Cancer Clinical Trial Working Group [10], the decreasing rate of PSA of each patient is shown in the waterfall plot. The decreasing rate of PSA was obtained from the value determined just before the initiation of treatment with DTX and the lowest value of PSA during treatment. Patients with a PSA decrease rate of $50 \%$ or more were defined as PSA responders and those with a rate of $0 \%$ or less were PSA nonresponders.

Secondary endpoints were time to progression (TTP) of PSA, OS, and toxicity. TTP was defined as the period from the initiation of treatment to PSA progression. PSA progression was defined as a $25 \%$ or greater increase and an absolute increase of $2 \mathrm{ng} / \mathrm{mL}$ or more from the nadir, which was confirmed by a second value obtained three or more weeks later. OS was defined as the period from the initiation of treatment to death. When patients were lost to follow-up, OS was considered up to the last day on which the patient survival was confirmed. 


\begin{tabular}{|c|c|c|c|}
\hline & $\begin{array}{l}\text { Docetaxel with estramustine } \\
(\mathrm{n}=33)\end{array}$ & $\begin{array}{l}\text { Docetaxel without estramustine } \\
(\mathrm{n}=28)\end{array}$ & p value* \\
\hline Age (years), median (range) & $67(55-88)$ & $72(50-82)$ & 0.062 \\
\hline PSA at PCa diagnosis (ng/ml), median(range) & $124.1(10.3-4116.0)$ & $102.1(4.7-19523.1)$ & 0.452 \\
\hline PSA at baseline (ng/ml), median(range) & $17.1(0.6-1053.0)$ & $11.4(0.8-618.4)$ & 0.633 \\
\hline Time from diagnosis to this chemothrapy (months), median(range) & $34(4-176)$ & $37(7-113)$ & 0.492 \\
\hline ECOG performance status, $\mathrm{n}(\%)$ & & & 0.299 \\
\hline 0 & $19(58)$ & $12(43)$ & \\
\hline 1 & $9(27)$ & $13(46)$ & \\
\hline 2 & $5(15)$ & $3(11)$ & \\
\hline Gleason score, n (\%) & & & 0.517 \\
\hline$<6$ & $2(6)$ & $2(7)$ & \\
\hline 7 & $9(27)$ & $4(14)$ & \\
\hline$>8$ & $20(61)$ & $19(68)$ & \\
\hline unknown & $2(6)$ & $3(11)$ & \\
\hline \multicolumn{4}{|l|}{ Metastatic site, n (\%) } \\
\hline Bone & $17(52)$ & $16(57)$ & 0.797 \\
\hline Lymph nodes & $10(30)$ & $11(39)$ & 0.590 \\
\hline Liver & $0(0)$ & $1(4)$ & 0.459 \\
\hline Lung & $3(9)$ & $0(0)$ & 0.243 \\
\hline None & $12(36)$ & $7(25)$ & 0.080 \\
\hline \multicolumn{4}{|l|}{ Prior treatment, n (\%) } \\
\hline MAB & $33(100)$ & $28(100)$ & ne \\
\hline Estramustine & $33(100)$ & $28(100)$ & ne \\
\hline Radical Prostatectomy & $2(6)$ & $1(4)$ & 1.000 \\
\hline Radiation Therapy & $4(12)$ & $3(11)$ & 1.000 \\
\hline Dexamethasone & $8(24)$ & $11(39)$ & 0.270 \\
\hline Other Chemotherapy & $6(18)$ & $8(29)$ & 0.375 \\
\hline No. of cycles, median (range) & $5(2-32)$ & $4(2-27)$ & 0.382 \\
\hline
\end{tabular}

* by Mann-Whitney $U$ test and chi-square test, PSA, prostate-specific antigen; PCa, Prostate Cancer; CRPC, Castration Resistant Prostate Cancer; ECOG, Eastern Cooperative Oncology Group; MAB, Maximum Androgen Blockage; ne, not evaluable

Adverse events were determined according to the classification by National Cancer Institute Common Toxicity Criteria (NCI-CTC), version 4.

\section{Statistics}

Mann-Whitney $U$ test or chi-square test was used for comparing clinical and pathological data, PSA response, and adverse events. TTP and OS were obtained by using Kaplan-Meier method and compared using log-rank test. Multivariate analysis was performed by using Cox proportional-hazard analysis for the identification of prognostic factors. Continuous data were divided into two groups according to median value. $\mathrm{P}$ value of less than 0.05 was judged as statistically significant.

\section{Results}

\section{Efficacy}

PSA response by group is shown in a waterfall plot (Figure 1). Six patients (21\%) in group D and eight patients (24\%) in group DE were PSA responders and 10 patients (36\%) in group D and 11 patients (33\%) in group DE were PSA nonresponders. There was no statistical difference in PSA response between these two groups ( $p=0.962)$.

The median TTP was 12.0 months (range; $1.5-54.3$ months) in group D and 6.2 months (range; $2.4-39.2$ months) in group DE (Figure 2A); further, the median OS was 26.4 months (range; 3.9-60.9 months) in group D and 24.3 months (range; $3.0-51.8$ months) in group DE (Figure 2B). There were no statistical differences in median TTP and OS between these two groups (TTP, p = 0.113 ; OS, $\mathrm{p}=0.853)$. Eight patients $(29 \%)$ in group D and 19 patients (58\%) in group DE died of cancer. The reasons for discontinuation were progression of disease in 18 patients $(64 \%)$ in group D and 22 patients $(67 \%)$ in group DE and the occurrence of adverse events in three patients (11\%) in group D and one patient (3\%) in group DE. Currently, four patients (14\%) in group D and six patients (18\%) in group DE are continuing the treatment.

\section{Subgroup analysis}

Univariate analysis using log-rank test revealed a significant association between OS and five factors (PSA at 

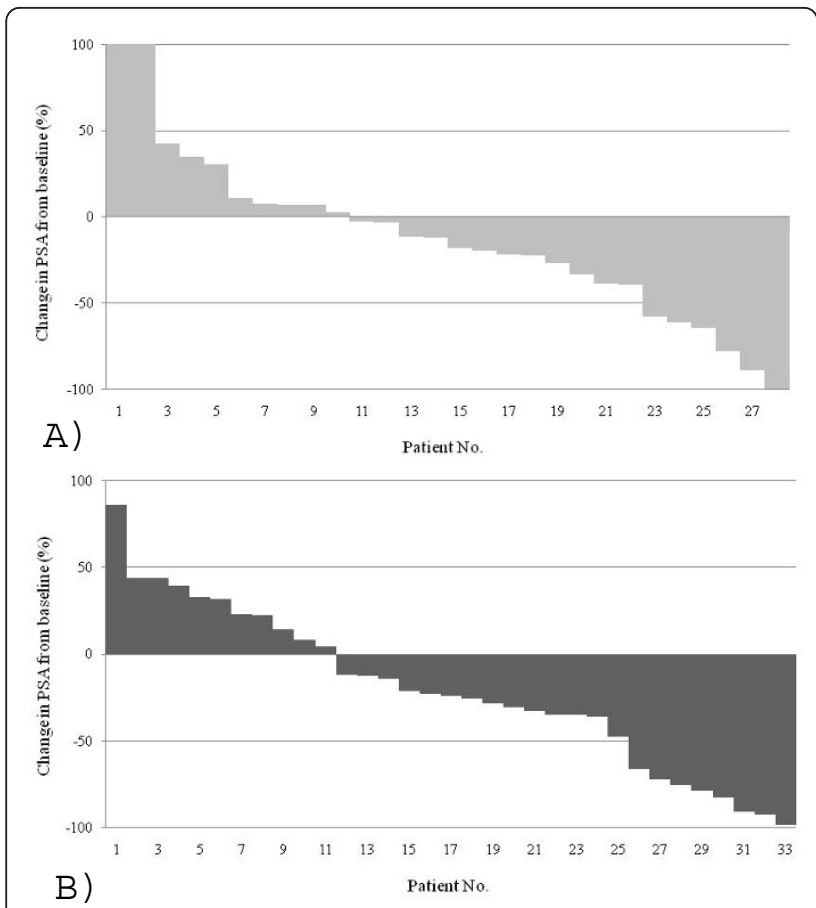

Figure 1 Waterfall plots of\% change in PSA after treatment by docetaxel without estramustine $(n=28 ; A)$ and with estramustine $(n=33 ; B)$.

baseline, ECOG performance status, time from diagnosis to DTX chemotherapy, bone metastasis, and the number of DTX cycles). These five factors were used in multivariate analysis. A PSA value $>12.8 \mathrm{ng} / \mathrm{mL}$ at baseline indicated significantly worse prognosis, and 35 months or more period from the diagnosis to DTX chemotherapy and five or more cycles of DTX suggested significantly better prognosis. The presence or absence of EMP with DTX was not a prognostic factor (Table 2). Multivariate analysis using six factors, which included the five above-mentioned factors and treatment factor (group D vs group DE), revealed the same results as shown in Table 2, indicating that addition of EMP to DTX is not associated with prognosis (data not shown).

\section{Toxicity}

Adverse events are shown in Table 3. There was no statistical difference between the two groups based on the incidence of grade 3/4 adverse events. The most frequent adverse events were neutropenia $(\mathrm{n}=19,68 \%)$ in group $\mathrm{D}$ and leukopenia $(\mathrm{n}=15,45 \%)$ in group $\mathrm{DE}$. The most frequent grade 3/4 adverse event was neutropenia in the both groups; 14 patients $(50 \%)$ in group D and 11 patients (33\%) in group DE had neutropenia. Although there were no significant differences in the incidence of leukopenia and neutropenia between the two groups, these effects were less common in group

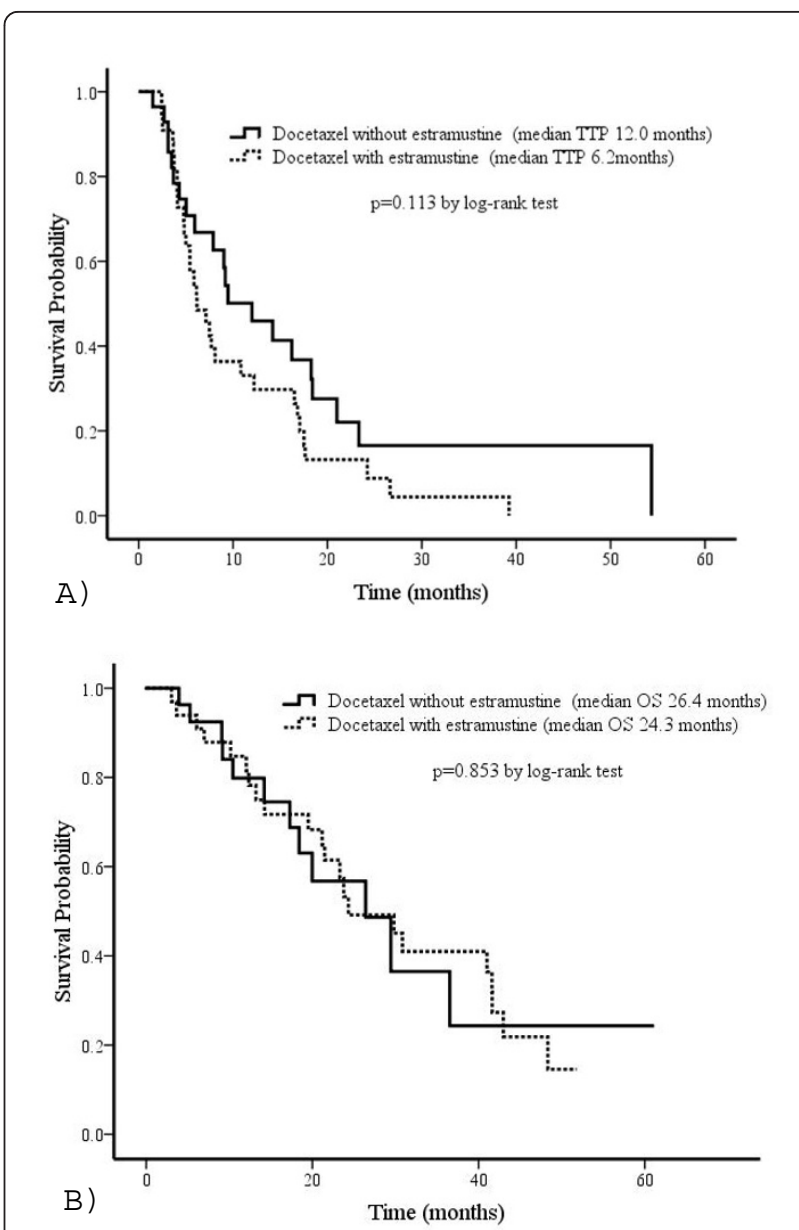

Figure 2 Time to PSA progression (A) and overall survival (B) in patients treated by docetaxel with or without estramustine.

DE than in group D. Further, grade 2 thromboembolism in one patient and interstitial pneumonia in one patient were observed in group DE; however, there was no treatment-related death in any group. In addition, gastrointestinal symptoms (anorexia, nausea, and diarrhea), fatigue, and alopecia were frequently observed in the both the groups. Grade 3 allergic reaction was observed in one patient in group DE and taste disorder was observed in two patients (one patient in group D and one patient in group DE).

\section{Discussion}

The significance of addition of EMP to DTX therapy in CRPC patients is still controversial in clinical trials [3-6] as well as preclinical studies [7-9]. Therefore, it is reasonable to compare the clinical efficacy of DTX + EMP combination with DTX alone in EMP-refractory CRPC patients in order to elucidate the significance of addition of EMP to DTX therapy. Present retrospective study showed, for the first time, that there were no significant 
Table 2 Prognostic factors for overall survival by univariate and multivariate Cox regression analysis

\begin{tabular}{|c|c|c|c|c|c|c|c|c|c|c|}
\hline \multirow{2}{*}{ parameter } & \multirow[b]{2}{*}{ category } & \multicolumn{2}{|r|}{ Univariate } & \multicolumn{7}{|c|}{ Multivariate } \\
\hline & & $\mathrm{n}$ & Hazard ratio & \multicolumn{2}{|c|}{$95 \% \mathrm{Cl}$} & \multirow{2}{*}{$\begin{array}{c}\mathbf{p} \text { value } \\
0.853\end{array}$} & Hazard ratio & \multicolumn{2}{|c|}{$95 \% \mathrm{Cl}$} & \multirow[t]{2}{*}{$p$ value } \\
\hline Treatment & D & 28 & 1.000 & & & & & & & \\
\hline & $\mathrm{DE}$ & 33 & 0.934 & 0.454 & 1.923 & & & & & \\
\hline Age (years) & $\leqq 70$ & 30 & 1.000 & & & 0.549 & & & & \\
\hline & $>70$ & 31 & 0.808 & 0.401 & 1.628 & & & & & \\
\hline Gleason Score & $\leqq 7$ & 17 & 1.000 & & & 0.259 & & & & \\
\hline & $>8$ & 39 & 1.558 & 0.718 & 3.381 & & & & & \\
\hline PSA at PCa diagnosis (ng/ml) & $\leqq 113$ & 31 & 1.000 & & & 0.940 & & & & \\
\hline & $>113$ & 30 & 1.027 & 0.520 & 2.025 & & & & & \\
\hline PSA at baseline (ng/ml) & $\leqq 12.8$ & 31 & 1.000 & & & $<0.001$ & 1.000 & & & 0.017 \\
\hline & $>12.8$ & 30 & 4.903 & 2.181 & 11.024 & & 3.605 & 1.262 & 10.296 & \\
\hline ECOG performance status & $\leqq 1$ & 53 & 1.000 & & & $<0.001$ & 1.000 & & & 0.218 \\
\hline & 2 & 8 & 5.567 & 2.366 & 13.098 & & 1.803 & 0.706 & 4.605 & \\
\hline Time from diagnosis to this chemothrapy (months) & $\leqq 35$ & 31 & 1.000 & & & 0.003 & 1.000 & & & 0.015 \\
\hline & $>35$ & 30 & 0.351 & 0.172 & 0.715 & & 0.286 & 0.104 & 0.782 & \\
\hline Bone metastasis & no & 28 & 1.000 & & & 0.014 & 1.000 & & & 0.419 \\
\hline & yes & 33 & 2.383 & 1.165 & 4.873 & & 0.646 & 0.224 & 1.862 & \\
\hline No. of Docetaxel cycles & $<5$ & 28 & 1.000 & & & $<0.001$ & 1.000 & & & $<0.001$ \\
\hline & $<5$ & 33 & 0.213 & 0.100 & 0.452 & & 0.209 & 0.093 & 0.472 & \\
\hline Hemoglobin (g/dl) & $\leqq 12.0$ & 33 & 1.000 & & & 0.120 & & & & \\
\hline & $>12.0$ & 28 & 0.580 & 0.289 & 1.163 & & & & & \\
\hline
\end{tabular}

$\mathrm{Cl}$, confidence interval; D, Docetaxel without estramustine; DE, Docetaxel with estramustine; PSA, prostate-specific antigen; PCa, Prostate Cancer; ECOG, Eastern Cooperative Oncology Group; CRPC, Castration Resistant Prostate Cancer

Table 3 Acute adverse events according to NCI-CTC

\begin{tabular}{|c|c|c|c|c|c|c|c|c|c|}
\hline & \multicolumn{4}{|c|}{$\begin{array}{l}\text { Docetaxel with estramustine } \\
\qquad(\mathrm{n}=33)\end{array}$} & \multicolumn{4}{|c|}{$\begin{array}{l}\text { Docetaxel without estramustine } \\
\qquad(\mathrm{n}=28)\end{array}$} & \multirow{3}{*}{$p$ value $* *$} \\
\hline & \multicolumn{2}{|c|}{ Any grade* } & \multicolumn{2}{|c|}{ Grade3-4 } & \multicolumn{2}{|c|}{ Any grade } & \multicolumn{2}{|c|}{ Grade3-4 } & \\
\hline & $\mathrm{n}$ & $\%$ & $\mathrm{n}$ & $\%$ & $\mathrm{n}$ & $\%$ & $\mathrm{n}$ & $\%$ & \\
\hline Leukopenia & 15 & 45 & 7 & 21 & 18 & 64 & 11 & 39 & 0.123 \\
\hline Neutropenia & 13 & 39 & 11 & 33 & 19 & 68 & 14 & 50 & 0.187 \\
\hline Febrile neutropenia & 0 & 0 & 1 & 3 & 0 & 0 & 0 & 0 & 0.353 \\
\hline Anemia & 9 & 27 & 1 & 3 & 5 & 18 & 2 & 7 & 0.443 \\
\hline Thrombocytopenia & 0 & 0 & 0 & 0 & 0 & 0 & 0 & 0 & ne \\
\hline Fatigue & 10 & 30 & 0 & 0 & 10 & 36 & 0 & 0 & ne \\
\hline Anorexia & 10 & 30 & 0 & 0 & 10 & 36 & 1 & 4 & 0.274 \\
\hline Nausea & 13 & 39 & 2 & 6 & 10 & 36 & 0 & 0 & 0.185 \\
\hline Diarrhea & 4 & 12 & 0 & 0 & 2 & 7 & 0 & 0 & ne \\
\hline Taste alteration & 1 & 3 & 0 & 0 & 1 & 4 & 0 & 0 & ne \\
\hline Dizziness & 3 & 9 & 0 & 0 & 2 & 7 & 0 & 0 & ne \\
\hline Flushing & 2 & 6 & 0 & 0 & 0 & 0 & 0 & 0 & ne \\
\hline Edema & 1 & 3 & 0 & 0 & 2 & 7 & 0 & 0 & ne \\
\hline AST/ALT & 1 & 3 & 0 & 0 & 0 & 0 & 0 & 0 & ne \\
\hline Allergic reaction & 1 & 3 & 1 & 3 & 1 & 4 & 0 & 0 & 0.353 \\
\hline Pulmonary fibrosis & 1 & 3 & 1 & 3 & 0 & 0 & 0 & 0 & 0.353 \\
\hline Hair loss & 14 & 42 & 0 & 0 & 12 & 43 & 0 & 0 & ne \\
\hline Mood alteration & 1 & 3 & 0 & 0 & 0 & 0 & 0 & 0 & ne \\
\hline Neuropathy & 1 & 3 & 0 & 0 & 1 & 4 & 0 & 0 & ne \\
\hline Thromboembolic event & 1 & 3 & 0 & 0 & 0 & 0 & 0 & 0 & ne \\
\hline
\end{tabular}

* Grade by National Cancer Institute-Common Toxicity Criteria; ${ }^{* *}$ indicates the difference of the rate of grade $3-4$ adverse events between two regimens by chisquare test; ne, not evaluable 
differences in OS, TTP, PSA response, and adverse events between group D and group DE in EMP-refractory CRPC patients, suggesting that addition of EMP to DTX therapy had no survival benefit.

The PSA response (> 50\% decline in PSA) in SWOG 9916 [2] was 50\%. However, the PSA response in this study was low; only $21 \%$ patients in group D and $24 \%$ patients in group DE responded to treatment with 60 $\mathrm{mg} / \mathrm{m}^{2}$ DTX, which was similar to the regimen of SWOG 9916. Our result is consistent with that of another study in which patients who had been treated with EMP showed a lower PSA response as compared to patients without a history of EMP treatment [11], suggesting that treatment with EMP before DTX treatment decreases the PSA response. However, the median OS in group D was 26 months and that in group DE was 24 months. Further, these median OS are not only greater than that of nine months after treatment with $55 \mathrm{mg} / \mathrm{m}^{2}$ DTX [12] or that of 18 months after treatment with $60 \mathrm{mg} / \mathrm{m}^{2}$ DTX in SWOG 9916 but also consistent with the 15-27 months median OS obtained after treatment with $70-75 \mathrm{mg} / \mathrm{m}^{2}$ DTX $[1,4-6,13,14]$. The median OS of 24 months or more achieved in this study was considered to be due to the initiation of DTX therapy with low PSA value as compared with that obtained in the previous reports $[1,4-6,13,14]$, because multivariate analysis performed in this study and the report by Bamias et al. [15] demonstrated that OS prolonged when PSA was low at the initiation of DTX therapy. Since the adverse events observed in this study were well tolerated, treatment with $60 \mathrm{mg} / \mathrm{m}^{2}$ DTX seems to be effective and safe even in EMP-refractory CRPC patients. In recent years, several novel agents such as abiraterone [16], sipuleucel-T [17] and MDV3100 [18] have been developed and showed significant clinical efficacy against CRPC. Treatment with these agents would provide the survival benefit for CRPC patients.

Regarding adverse events in TAX 327 and SWOG 9916 , the incidences of grade $3 / 4$ neutropenia were $32 \%$ and 13\% in TAX 327 [1] (DTX, $75 \mathrm{mg} / \mathrm{m}^{2}$ ) and SWOG 9916 [2] (DTX, $60 \mathrm{mg} / \mathrm{m}^{2}$ ), respectively. Further, the incidence of grade $3 / 4$ neutropenia in clinical trials performed in Japan was $93 \%$ and $33 \%$ after treatment with $70 \mathrm{mg} / \mathrm{m}^{2}$ [19] and $55 \mathrm{mg} / \mathrm{m}^{2}$ DTX [12], respectively, indicating high incidences of DTX toxicity. In addition, the incidence of neutropenia after $60 \mathrm{mg} / \mathrm{m}^{2}$ DTX treatment was $86 \%$ in a clinical study on Japanese pancreatic cancer patients [20], suggesting that the incidence of neutropenia is high among Japanese patients. Although the sample size of our study was small, the incidence of grade $3 / 4$ neutropenia was $50 \%$ and $33 \%$ in group D and DE, respectively, which were higher as compared to the values reported in SWOG 9916 using $60 \mathrm{mg} / \mathrm{m}^{2}$ DTX.
However, no incidence of death or severe complications suggested that our treatment was well tolerated. Furthermore, grade 2 thromboembolism was observed in one patient (3\%) of group DE. Since EMP increases the incidence of thromboembolism $[2,3,6]$, it should be used with caution. The reason why the incidence of adverse events was not significant between group D and DE might be due to the means of treatment assignment. Namely, two-thirds of patients with adverse events by EMP monotherapy and those without them were classified in group D and DE, respectively. Although addition of EMP to DTX therapy might not show any survival benefit in CRPC patients, it was of interest that addition of EMP to DTX therapy lowered the incidence of grade $3 / 4$ neutropenia $(50 \%$ in group $\mathrm{D}$ and $33 \%$ in group $\mathrm{DE}$ ), though not by a significant extent. Meta-analysis [3] of chemotherapy combined with EMP showed a significantly low incidence of neutropenia due to concomitant use of EMP in the chemothrapy. In addition, treatment with EMP showed increase in the leukocyte count in patients with hormone-naïve prostate cancer [21] or CRPC [22]. Taken together, it is suggested that EMP increases the leukocyte count leading to the myeloprotection in the chemotherapy, albeit under limited conditions; hence, the significance of addition of EMP to DTX therapy may be attributed to the myeloprotection rather than the survival benefit. Further studies are required to clarify this point.

Multivariate analysis performed in this study revealed that PSA at baseline, time from diagnosis to DTX chemotherapy and the number of DTX cycles were related to the prognosis. Although these factors were statistically significant, the definitive conclusions cannot be drawn because of the small number of death events observed in this study. These factors have been reported as prognostic factors in other studies [11,15,23,24]; hence, DTX treatment should be introduced when PSA values are low and continued for as long as possible. However, addition of EMP did not serve as a prognostic factor.

This study has some limitations; it is a retrospective study with a small sample size and not a randomized clinical trial. However, it was concluded that addition of EMP to DTX therapy might not show any survival benefit in EMP-refractory CRPC patients although treatment with $60 \mathrm{mg} / \mathrm{m}^{2}$ DTX had the OS and toxicity profiles comparable to those in TAX 327 and SWOG 9916. Further studies would be needed to elucidate the significance of addition of EMP to DTX therapy.

\section{Conclusions}

Although treatment with DTX at $60 \mathrm{mg} / \mathrm{m}^{2}$ was effective and highly tolerated in EMP-refractory Japanese 


\section{CRPC patients, addition of EMP to DTX therapy might not show any survival benefit in CRPC patients.}

\section{Acknowledgements}

We thank Mayumi Takasawa for the assistance with manuscript preparation.

\section{Authors' contributions}

This study has been designed by KN and TM. The clinical database of the patients have been acquired by KN, SO, KK, TK, AN, KS, SK, MK and TM. Manuscript has been written by KN and TM. KN is responsible for the statistical analyses. Conclusions have been drawn mainly by KN and TM. TM has given final approval of the version to be published. All authors read and approved the final manuscript.

\section{Competing interests}

The authors declare that they have no competing interests.

Received: 9 October 2011 Accepted: 22 February 2012

Published: 22 February 2012

\section{References}

1. Tannock IF, de Wit R, Berry WR, Horti J, Pluzanska A, Chi KN, Oudard S, Theodore C, James ND, Turesson I, et al: Docetaxel plus prednisone or mitoxantrone plus prednisone for advanced prostate cancer. New EnglJ Med 2004, 351:1502-1512.

2. Petrylak DP, Tangen CM, Hussain MHA, Lara PJ, Jones JA, Taplin ME, Burch PA, Berry D, Moinpour C, Kohli M, et al: Docetaxel and estramustine compared with mitoxantrone and prednisone for advanced refractory prostate cancer. New Engl I Med 2004, 351:1513-1520.

3. Fizazi K, Le Maitre A, Hudes G, Berry WR, Kelly WK, Eymord JC, Logothetis CJ, Pignon JP, Michiels S, Grp METC: Addition of estramustine to chemotherapy and survival of patients with castration-refractory prostate cancer: a meta-analysis of individual patient data. Lancet Oncol 2007, 8:994-1000.

4. Eymard JC, Priou F, Zannetti A, Ravaud A, Lepille D, Kerbrat P, Gomez P, Paule B, Genet D, Herait P, et al: Randomized phase II study of docetaxel plus estramustine and single-agent docetaxel in patients with metastatic hormone-refractory prostate cancer. Ann Oncol 2007, 18:1064-1070.

5. Caffo O, Sava T, Comploj E, Fariello A, Zustovich F, Segati R, Sacco C, Valduga F, Cetto G, Galligioni E: Docetaxel, with or without estramustine phosphate, as first-line chemotherapy for hormone-refractory prostate cancer: results of a multicentre, randomized phase II trial. BJU Int 2008, 102:1080-1085.

6. Machiels JP, Mazzeo F, Clausse M, Filleul B, Marcelis L, Honhon B, D'Hondt L, Dopchie C, Verschaeve V, Duck L, et al: Prospective randomized study comparing docetaxel, estramustine, and prednisone with docetaxel and prednisone in metastatic hormone-refractory prostate cancer. J Clin Oncol 2008, 26:5261-5268.

7. Fizazi K, Sikes CR, Kim J, Yang J, Martinez LA, Olive MC, Logothetis CJ, Navone NM: High efficacy of docetaxel with and without androgen deprivation and estramustine in preclinical models of advanced prostate cancer. Anticancer Res 2004, 24:2897-2903.

8. Williams JF, Muenchen HJ, Kamradt JM, Korenchuk S, Pienta KJ: Treatment of androgen-independent prostate cancer using antimicrotubule agents docetaxel and estramustine in combination: an experimental study. Prostate 2000, 44:275-278.

9. Oudard S, Legrier ME, Boye K, Bras-Goncalves R, De Pinieux G, De Cremoux P, Poupon MF: Activity of docetaxel with or without estramustine phosphate versus mitoxantrone in androgen dependent and independent human prostate cancer xenografts. J Urol 2003, 169:1729-1734.

10. Scher HI, Halabi S, Tannock I, Morris M, Sternberg CN, Carducci MA, Eisenberger MA, Higano C, Bubley GJ, Dreicer R, et al: Design and end points of clinical trials for patients with progressive prostate cancer and castrate levels of testosterone: recommendations of the Prostate Cancer Clinical Trials Working Group. J Clin Oncol 2008, 26:1148-1159.

11. Armstrong AJ, Tannock IF, de Wit R, George DJ, Eisenberger M, Halabi S: The development of risk groups in men with metastatic castration- resistant prostate cancer based on risk factors for PSA decline and survival. Eur J Cancer 2010, 46:517-525.

12. Miyoshi Y, Uemura H, Nakamura M, Hasumi H, Sugiura S, Makiyama K, Nakaigawa N, Kishida T, Ogawa T, Yao M, et al: Treatment of androgenindependent, hormone-refractory prostate cancer with docetaxel in Japanese patients. Int J Clin Oncol 2005, 10:182-186.

13. Saad F, Ruether D, Ernst S, North S, Cheng T, Perrotte P, Karakiewicz P, Winquist E: The Canadian Uro-Oncology Group multicentre phase II study of docetaxel administered every 3 weeks with prednisone in men with metastatic hormone-refractory prostate cancer progressing after mitoxantrone/prednisone. BJU Int 2008, 102:551-555.

14. Matsumoto A, Inoue A, Yokoi S, Nozumi K, Miyazaki K, Hosoki S, Nagata M, Yamaguchi K: Evaluation of docetaxel plus estramustine in the treatment of patients with hormone-refractory prostate cancer. Int J Urol 2009, 16:687-691.

15. Bamias A, Bozas G, Antoniou N, Poulias I, Katsifotis H, Skolarikos A, Mitropoulos D, Alamanis C, Alivizatos G, Deliveliotis H, et al: Prognostic and predictive factors in patients with androgen-independent prostate cancer treated with docetaxel and estramustine: a single institution experience. Eur Urol 2008, 53:323-332.

16. de Bono JS, Logothetis CJ, Molina A, Fizazi K, North S, Chu L, Chi KN, Jones RJ, Goodman OB Jr, Saad F, et al: Abiraterone and increased survival in metastatic prostate cancer. N Engl J Med 2011, 364:1995-2005.

17. Kantoff PW, Higano CS, Shore ND, Berger ER, Small EJ, Penson DF, Redfern $\mathrm{CH}$, Ferrari AC, Dreicer R, Sims RB, et al: Sipuleucel-T immunotherapy for castration-resistant prostate cancer. N Engl J Med 2010, 363:411-422

18. Scher HI, Beer TM, Higano CS, Anand A, Taplin ME, Efstathiou E, Rathkopf D, Shelkey J, Yu EY, Alumkal J, et al: Antitumour activity of MDV3100 in castration-resistant prostate cancer: a phase 1-2 study. Lancet 2010, 375:1437-1446.

19. Naito S, Tsukamoto T, Koga H, Harabayashi T, Sumiyoshi Y, Hoshi S, Akaza $\mathrm{H}$ : Docetaxel plus prednisolone for the treatment of metastatic hormone-refractory prostate cancer: A multicenter phase II trial in Japan. Jpn J Clin Oncol 2008, 38:365-372.

20. Okada S, Sakata Y, Matsuno S, Kurihara M, Sasaki Y, Ohashi Y, Taguchi T: Phase II study of docetaxel in patients with metastatic pancreatic cancer: a Japanese cooperative study. Cooperative Group of Docetaxel for Pancreatic Cancer in Japan. Br J Cancer 1999, 80:438-443.

21. Daponte D, Sylvester R, De Pauw M, Fryszman A, Smith RM, Smith PH: Change in white cell count during treatment of advanced cancer of the prostate with estramustine phosphate and with stilboestrol. BJU Int 1983, 55:408-412.

22. Morita T: Marked leukocytosis in response to estramustine phosphate in a hormone-refractory prostate cancer patient. Int Med Case Reports J 2010, 3:39-41.

23. Armstrong AJ, Garrett-Mayer ES, Yang YCO, de Wit R, Tannock IF, Eisenberger M: A contemporary prognostic nomogram for men with hormone-refractory metastatic prostate cancer: a TAX327 study analysis. Clin Cancer Res 2007, 13:6396-6403.

24. Ide H, Kikuchi E, Kono H, Nagata H, Miyajima A, Nakagawa K, Ohigashi T, Nakashima J, Oya M: Docetaxel in Combination with Prednisolone for Hormone Refractory Prostate Cancer. Jpn J Clin Oncol 2010, 40:79-84.

\section{Pre-publication history}

The pre-publication history for this paper can be accessed here: http://www.biomedcentral.com/1471-2490/12/3/prepub

doi:10.1186/1471-2490-12-3

Cite this article as: Nakano et al:: Docetaxel with or without estramustine for estramustine refractory castration-resistant prostate cancer: a single institution experience. BMC Urology 2012 12:3. 